\title{
Migration Paths of Anthropogenic Cd to Jiaozhou Bay
}

\author{
Dongfang Yang ${ }^{1,2, a}$, Danfeng Yang ${ }^{3}$, Qi Wang ${ }^{1}$, Longlei Zhang ${ }^{1}$, Haixia Li $^{1}$ \\ ${ }^{1}$ Accountancy School, Xijing University, Xian 710123, China; \\ ${ }^{2}$ North China Sea Environmental Monitoring Center, SOA, Qingdao 266033, China; \\ ${ }^{3}$ The Fu Foundation School of Engineering and Applied Science, Columbia University, 10025, USA. \\ adfyang_dfyang@126.com
}

Keywords: Cadmium, Anthropogenic source, Migration path, Block diagram model, Jiaozhou Bay.

\begin{abstract}
Using investigation data on Cadmium (Cd) in May and August 1990, this paper analyzed the anthropogenic sources and migration paths of $\mathrm{Cd}$. Results showed that the major Cd sources were river discharge, atmosphere deposition and marine traffic, whose source strengths were 1.56 $\mu \mathrm{g} \mathrm{L}{ }^{-1}, 1.21-1.26 \mu \mathrm{g} \mathrm{L}^{-1}$ and $1.02 \mu \mathrm{g} \mathrm{L}{ }^{-1}$, respectively. The source strengths were all higher than 1.0 $\mu \mathrm{g} \mathrm{L}{ }^{-1}$ but lower than $5.0 \mu \mathrm{g} \mathrm{L}^{-1}$ that were conform to Grade II in according to China Sea Water Quality Standard (GB 3097-1997). The source strengths of Cd in study period were still weak in general. The migration paths of anthropogenic Cd to Jiaozhou Bay were 1) anthropogenic Cd was discharged to the land, 2) anthropogenic was discharged to the atmosphere, and 3) Cd was discharged to the ocean. Furthermore, a block diagram model was provided to demonstrate these migration paths.
\end{abstract}

\section{Introduction}

$\mathrm{Cd}$ is one of the widely used heavy metal elements in various industries. A large amount of Cd-containing wastes were generated and discharged to the land, atmosphere and ocean. Many marine bays have been polluted by Cd since ocean is the sink of pollutants [1-4]. Cd is high toxic, and the excess existence of $\mathrm{Cd}$ in the environmental could result in health risk. Understanding the migration paths of anthropogenic $\mathrm{Cd}$ to marine bay is essential to environmental protection and remediation [5-7]. Jiaozhou Bay is a semi-closed bay located in Shandong Province, China. Using investigation on Cd in May and August 1990, this paper analyzed the sources, sources strengths and migration paths of $\mathrm{Cd}$. The aim of this paper is to provide basis for research on the migration of $\mathrm{Cd}$ in marine bay.

\section{Study area and data source}

\subsection{Study area.}

Jiaozhou Bay $\left(120^{\circ} 04^{\prime}-120^{\circ} 23^{\prime}\right.$ E, $\left.35^{\circ} 55^{\prime}-36^{\circ} 18^{\prime} \mathrm{N}\right)$ is located in the south of Shandong Province, eastern China (Fig. 1). It is a semi-closed bay with the total area, average water depth and bay mouth width of $446 \mathrm{~km}^{2}, 7 \mathrm{~m}$ and $3 \mathrm{~km}$, respectively. There are more than ten inflow rivers such as Haibo Rriver, Licun Rriver, and Loushan Rriver [8-9].

\subsection{Data source.}

The data was provided by North China Sea Environmental Monitoring Center. The investigations were conducted in May and August 1990, respectively. Surface water samples in 13 sampling sites (i.e., 52, 53, 54, 55, 56, 57, 58, 59, 60, 61, 2104, 2105 and 2106) in May and 11 sampling sites (i.e., 52, 53, 54, 55, 57, 58, 59, 60, 61, 2105 and 2106) in August were collected and measured followed by National Specification for Marine Monitoring (Fig. 1) [10]. 


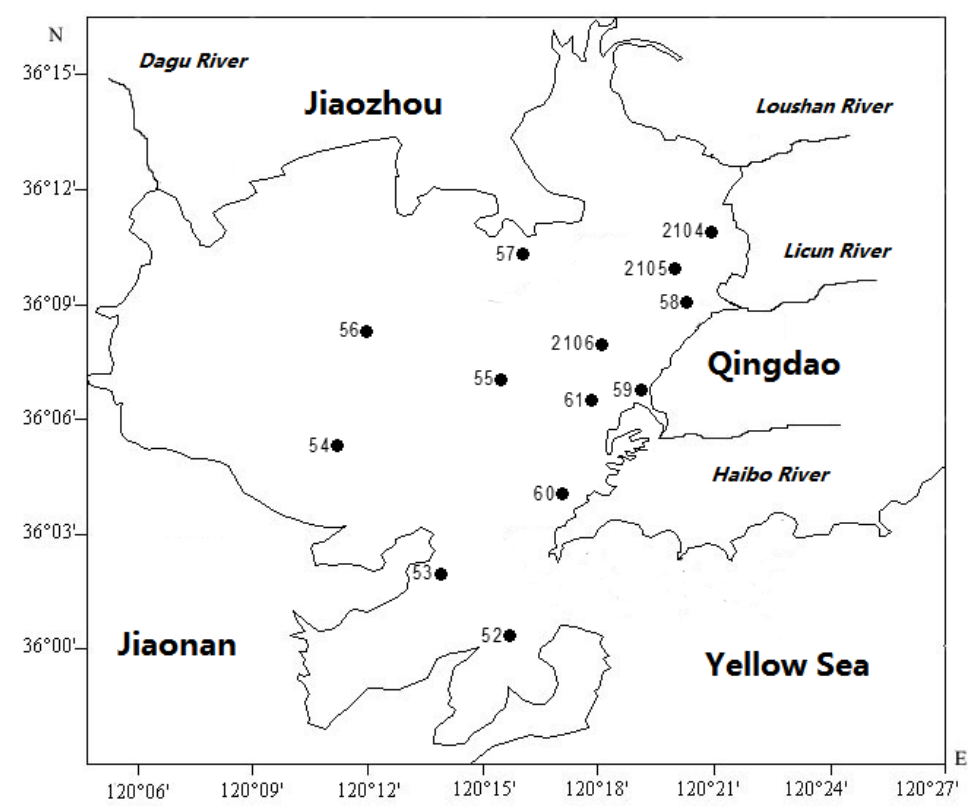

Fig. 1 Geographic location and monitoring sites in Jiaozhou Bay

\section{Results and discussion}

\subsection{Horizontal distribution of $\mathrm{Cd}$.}

In May and August 1990, Cd contents in surface waters in Jiaozhou Bay were 0.05-1.56 $\mu \mathrm{g}$ $\mathrm{L}^{-1}$ and 0.15-1.26 $\mu \mathrm{g} \mathrm{L}^{-1}$, respectively. In May 1990, there was a high value center in the estuary of Haibo River in the east of the bay, the contour lines of $\mathrm{Cd}$ contents were forming a series of semi-concentric circles. Meanwhile, there was another high value center in the wharf in the east of the bay, and the contour lines of Cd contents were forming a series of semi-rectangles. In general, Cd contents in May 1990 were decreasing along with the flow direction of Haibo River, and the distance from the wharf (Fig. 2). In August 1990, there was a high value center in the center of the bay, the contour lines of Cd contents were forming a series of concentric circles that decreasing from the bay center to waters around (Fig. 3).

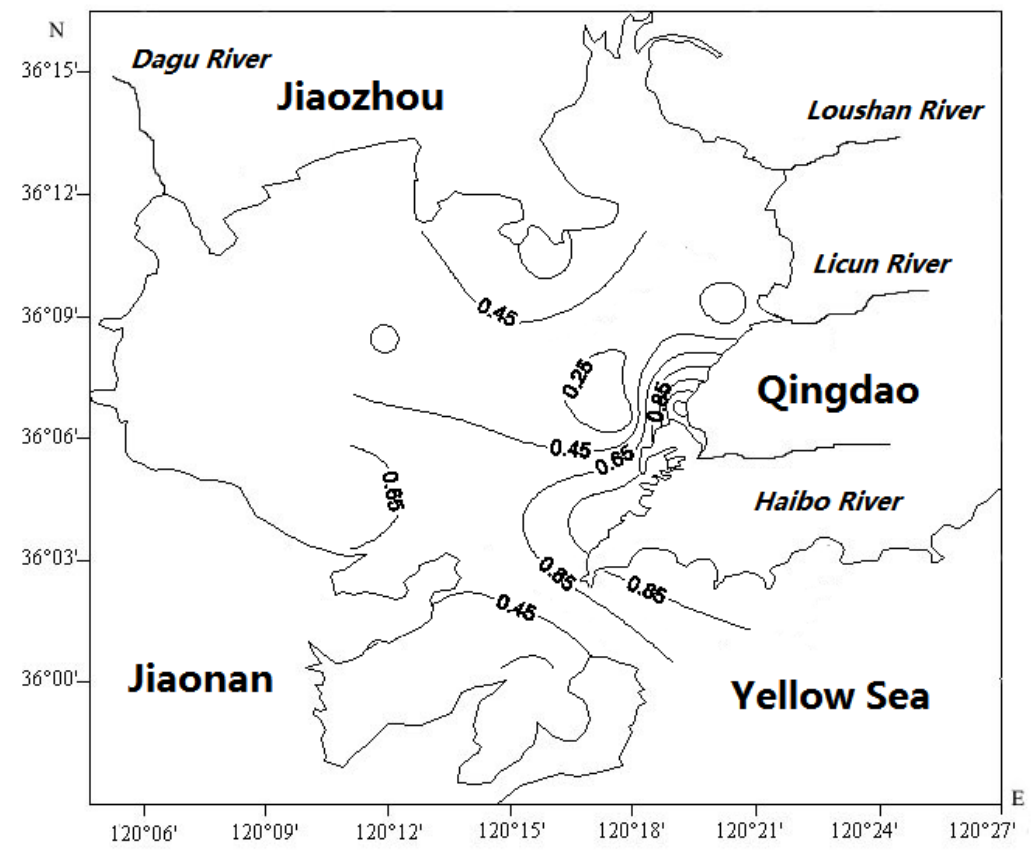

Fig. 2 Horizontal distributions of Cd in surface waters in Jiaozhou Bay in May 1990/ $\mu \mathrm{g}^{-1}$ 


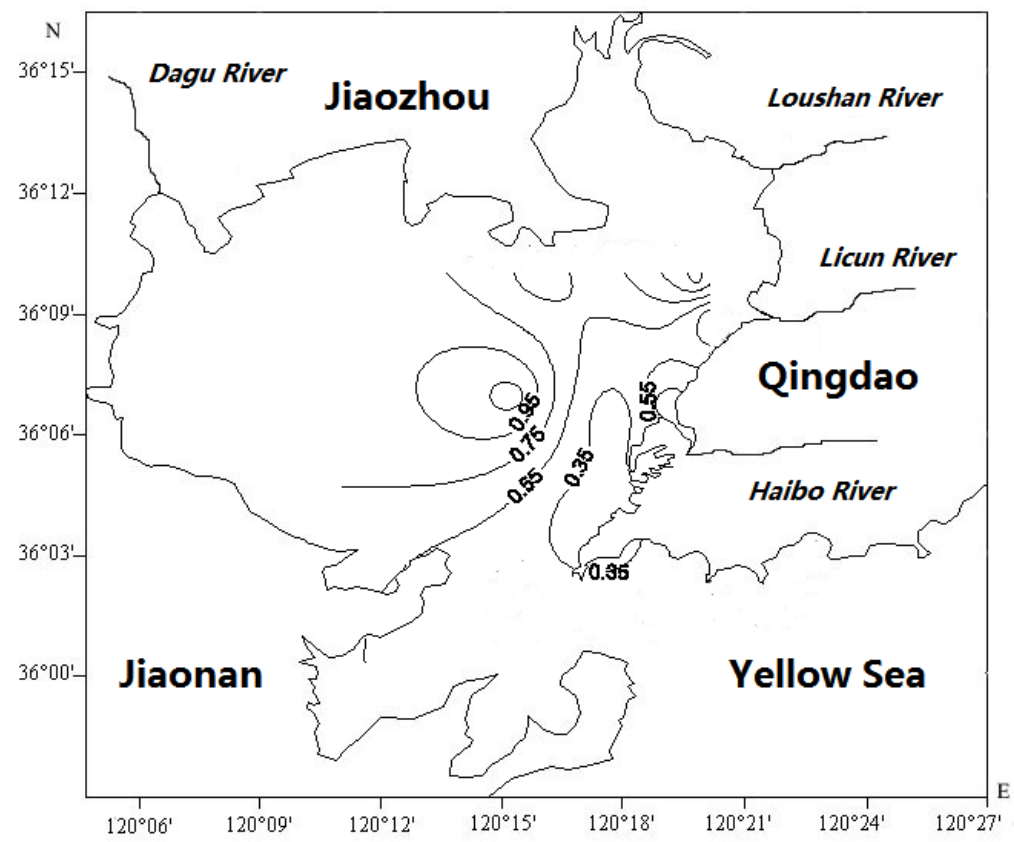

Fig. 3 Horizontal distributions of Cd in surface waters in Jiaozhou Bay in August 1990/ $\mu \mathrm{g} \mathrm{L}^{-1}$

\subsection{Pollution level of Cd.}

The China Sea Water Quality Standard (GB 3097-1997) establishes guide lines for Cd (Table 1). In May 1990, Cd contents in surface waters in the estuary of Haibo River and the wharf in the east of the bay in Jiaozhou Bay were higher than $1.0 \mu \mathrm{g} \mathrm{L}^{-1}\left(1.02-1.56 \mu \mathrm{g} \mathrm{L}^{-1}\right)$ that were confirm to Grade II, while in the other regions were lower than $1.0 \mu \mathrm{g} \mathrm{L}^{-1}$ that were confirm to Grade I. In August 1990, Cd contents in the center of the bay were higher than $1.0 \mu \mathrm{g} \mathrm{L}^{-1}\left(1.21-1.26 \mu \mathrm{g} \mathrm{L}^{-1}\right)$ that were confirm to Grade II, while in the other regions were lower than $1.0 \mu \mathrm{g} \mathrm{L}^{-1}$ that were confirm to Grade I. In general, the pollution level of the Cd in Jiaozhou Bay in 1990 was still very slight.

Table 1 China Sea Water Quality Standard (GB 3097-1997) guide lines for Cd

\begin{tabular}{cccc}
\hline Grade & I & II & III and $\mathrm{V}^{\mathrm{b}}$ \\
\hline Content $/ \mu \mathrm{g} \mathrm{L}^{-1}$ & 1.00 & 5.00 & 10.00 \\
\hline
\end{tabular}

${ }^{\mathrm{b}}$ Guide lines for Cd of Grade III and V are same.

\subsection{Source of Cd.}

Cd contents in surface waters were impacted by the source input directly, and therefore the major source could be identified by the horizontal of Cd. It could be seen from Fig. 2 and Fig. 3 that the major Cd sources in May 1990 were river discharge and marine traffic whose source strengths were $1.56 \mu \mathrm{g} \mathrm{L}^{-1}$ and 1.21-1.26 $\mathrm{g} \mathrm{L} \mathrm{L}^{-1}$, respectively,while in August 1990 were atmosphere deposition whose source strength was $1.02 \mu \mathrm{g} \mathrm{L}^{-1}$. The source strengths were all higher than $1.0 \mu \mathrm{g} \mathrm{L}^{-1}$ but lower than $5.0 \mu \mathrm{g} \mathrm{L}^{-1}$ that were conform to Grade II in according to China Sea Water Quality Standard (GB 3097-1997). The source strengths of Cd in study period were still weak in general. The migration paths of anthropogenic Cd to Jiaozhou Bay were 1) anthropogenic Cd was discharged to the land, 2) anthropogenic was discharged to the atmosphere, and 3) Cd was discharged to the ocean (Fig. 4). 


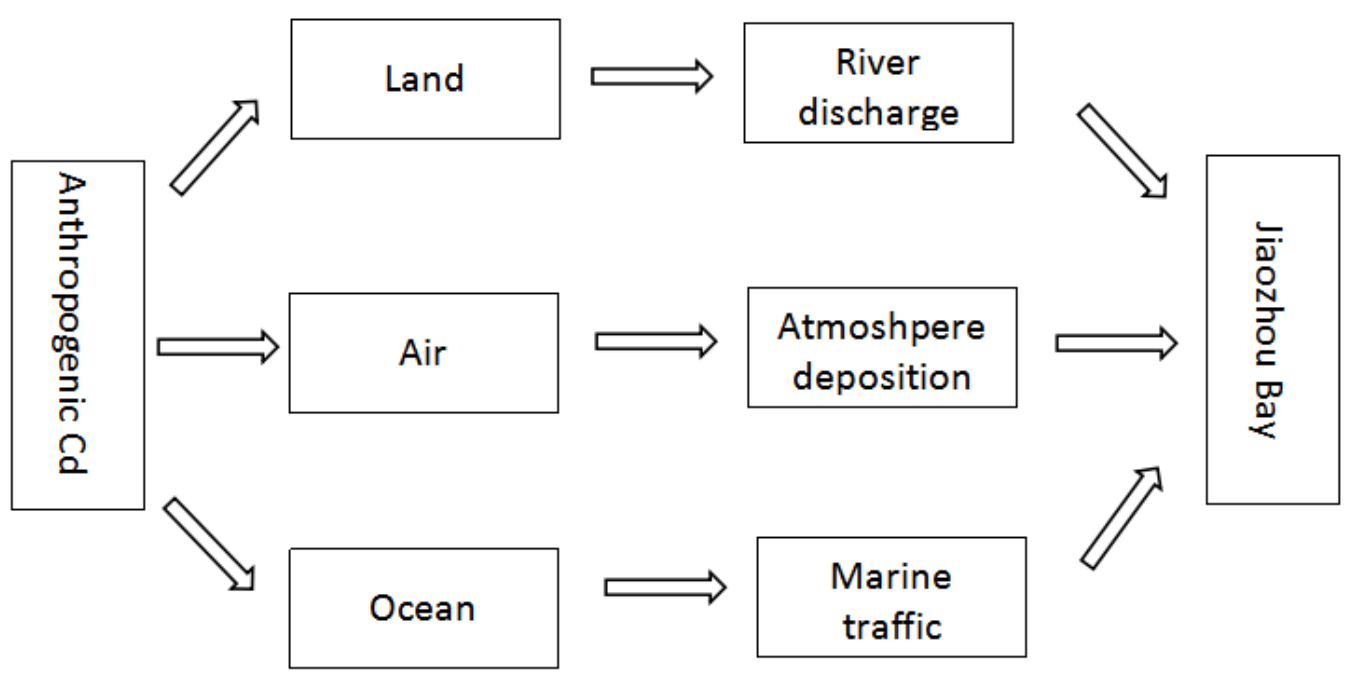

Fig. 4 Block diagram model for migration paths of anthropogenic Cd to Jiaozhou Bay

\section{Conclusion}

In May and August 1990, Cd contents in surface waters in Jiaozhou Bay were 0.05-1.56 $\mu \mathrm{g}$ $\mathrm{L}^{-1}$ and 0.15-1.26 $\mu \mathrm{g} \mathrm{L}^{-1}$, respectively. The pollution level of the Cd in Jiaozhou Bay in 1990 was still very slight. The major $\mathrm{Cd}$ sources were river discharge, atmosphere deposition and marine traffic, whose source strengths were $1.56 \mu \mathrm{g} \mathrm{L} \mathrm{L}^{-1}, 1.21-1.26 \mu \mathrm{g} \mathrm{L}^{-1}$ and $1.02 \mu \mathrm{g} \mathrm{L}{ }^{-1}$, respectively. The source strengths of Cd in study period were still weak. The migration paths of anthropogenic Cd to Jiaozhou Bay were 1) anthropogenic Cd was discharged to the land, 2) anthropogenic was discharged to the atmosphere, and 3) Cd was discharged to the ocean. These migration paths were demonstrated by the block diagram model.

\section{Acknowledgements}

This research was sponsored by Doctoral Degree Construction Library of Guizhou Nationalities University and Research Projects of Guizhou Nationalities University ([2014]02), Research Projects of Guizhou Province Ministry of Education (KY [2014] 266), Research Projects of Guizhou Province Ministry of Science and Technology (LH [2014] 7376).

\section{References}

[1] Yang DF and Miao ZQ: Marine Bay Ecology (I): Beijing, Ocean Precess, (2010), p. 1-320.

[2] Yang DF and Gao ZH: Marine Bay Ecology (II): Beijing, Ocean Precess, (2010), p. 1-330.

[3] Yang DF, Chen Y, Wang H, et al.: Coastal Engineering, Vol. 29 (2010), p. 73-82.

[4] Yang DF, Chen Y, Liu CX, et al.: Coastal Engineering, Vol. 32(2013), p. 68-78.

[5] Yang DF, Zhu SX, Wu YF, et al.: Applied Mechanics and Materials, Vol.644-650 (2014), p. 5325-5328.

[6] Yang DF, Wang FY, Wu FY, et al.: Applied Mechanics and Materials, Vol .644-650 (2014), p. 5329-5312.

[7] Yang DF, Chen ST, Li BL, et al.:Proceedings of the 2015 international symposium on computers and informatics, 2015, p. 2667-2674.

[8] Yang DF, Chen Y, Gao ZH, et al.: Chinese Journal of Oceanology and Limnology, Vol. 23(2005), p. 72-90.

[9] Yang DF, Wang FY, Gao ZH, et al.: Marine Science, Vol. 28 (2004), p. 71-74.

[10] China's State Oceanic Administration: The specification for marine monitoring (Ocean Press, Beijiang 1991), p.1-300. 